\title{
Bilateral Knee Synovial Osteochondromatosis: A Case Report
}

\author{
Nazia Naz S. KHAN, Rajaie NAMAS, Sally Jo SPERBECK, Harpreet SAGAR
}

Department of Internal Medicine, Division of Rheumatology Wayne State University, Detroit, Michigan, USA

\begin{abstract}
Synovial osteochondromatosis or synovial chondrometaplasia is an uncommon benign condition involving large joints such as the knee, hip, and elbow characterized by proliferation of the synovium with cartilaginous metaplasia. In this article, we report an 85-year-old woman with bilateral knee pain and swelling secondary to bilateral synovial osteochondromatosis. The condition needs attention due to its high morbidity rates and although rare, malignant transformation can occur.

Keywords: Primary synovial chondromatosis; synovial chondrometaplasia; synovial osteochondromatosis.
\end{abstract}

Synovial osteochondromatosis (SOC) is a rare and benign monoarticular arthropathy characterized by multi-nodular cartilaginous proliferation in the synovium of the joint, tendon sheath or bursa. ${ }^{1}$ All major joints including the knee particularly can be affected, followed by the hip, elbow, wrist, ankle, and shoulder joints. Patients usually present in the second to fifth decades of life. Typical symptoms include pain, antalgic gait, locking, and a restricted range of motion. This condition is often considered a metaplastic process, and is usually self-limiting.

\section{CASE REPORT}

An 85-year-old Afro-American woman with a history of hypertension, type 2 diabetes mellitus, and degenerative arthritis was admitted to the emergency department with bilateral knee pain which led to frequent falls. The rheumatology service was consulted for bilateral knee pain and swelling. Four months prior to admission, the patient noticed that the pain and swelling in her knees worsened, increased by carrying weight and performing daily activities, and relieved by rest. She was using a cane to walk for the past few years. However, she was admitted on a wheelchair or walker. She had also a history of intermittent locking in both knees. No recent major trauma was reported except for some abrasions from falls. Family history was remarkable for degenerative arthritis in both parents.

On physical examination, the patient appeared in moderate distress due to joint pain. Her vital signs at baseline were as follows: blood pressure: 120/72 mmHg, respiratory rate: $19 \mathrm{bpm}$, pulse: $95 \mathrm{bpm}$, temperature: $37.1{ }^{\circ} \mathrm{C}$, oxygen saturation: $100 \%$ in room air. Her weight was $70 \mathrm{~kg}$ with a body mass index of $23 \mathrm{~kg} / \mathrm{m}^{2}$. She was oriented to person, place, and time.

Musculoskeletal examination findings were as follows;

- Hands: Heberden's and Bouchard's nodes in the proximal interphalangeal and distal interphalangeal joints bilaterally. No active synovitis.

- Hip joint: Full range of motion in all planes. 
- Knee: Healing abrasions on the anterior aspect both knees. Bilateral bony overgrowth, mild warmth and small effusion in the knee joints. Bilateral joint line tenderness. Bilateral reduction in knee flexion contractures, and limitation in the range of motion.

- Ankle and Feet: Full range of motion with no active synovitis.

Other physical examination results were nonspecific.

Plain radiographs of the knee joints revealed joint effusions with multiple rounded intraarticular loose bodies, erosions on the medial
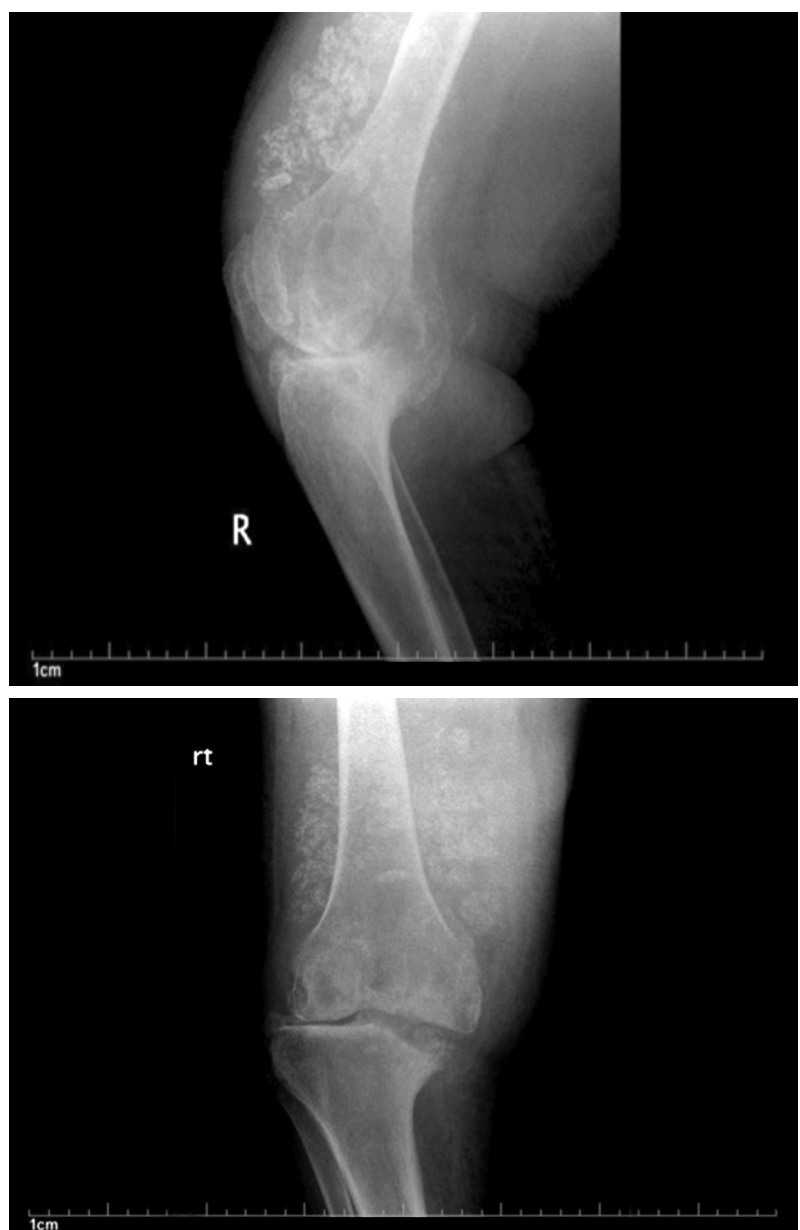

Figure 1. Anteroposterior and lateral X-ray of the right knee showing severe synovial osteochondromatosis of the joint with associated arthritic changes, large joint effusion and subluxation of the tibial femoral joint. aspect of the tibial plateau, tricompartmental joint space narrowing, osteophytes, subchondral cyst formation, heterotopic bone formation, and lateral subluxation of the tibia on the femur (Figure 1, 2).

The patient was diagnosed with SOC, based on the presentation with chronic oligoarticular synovitis in the knees, and the X-ray findings. The consulting rheumatology and orthopedic services recommended conservative management due to the patient's global health status, and in accordance with her wishes. The patient was subsequently transferred to a nursing home with instructions to use hinged knee braces.
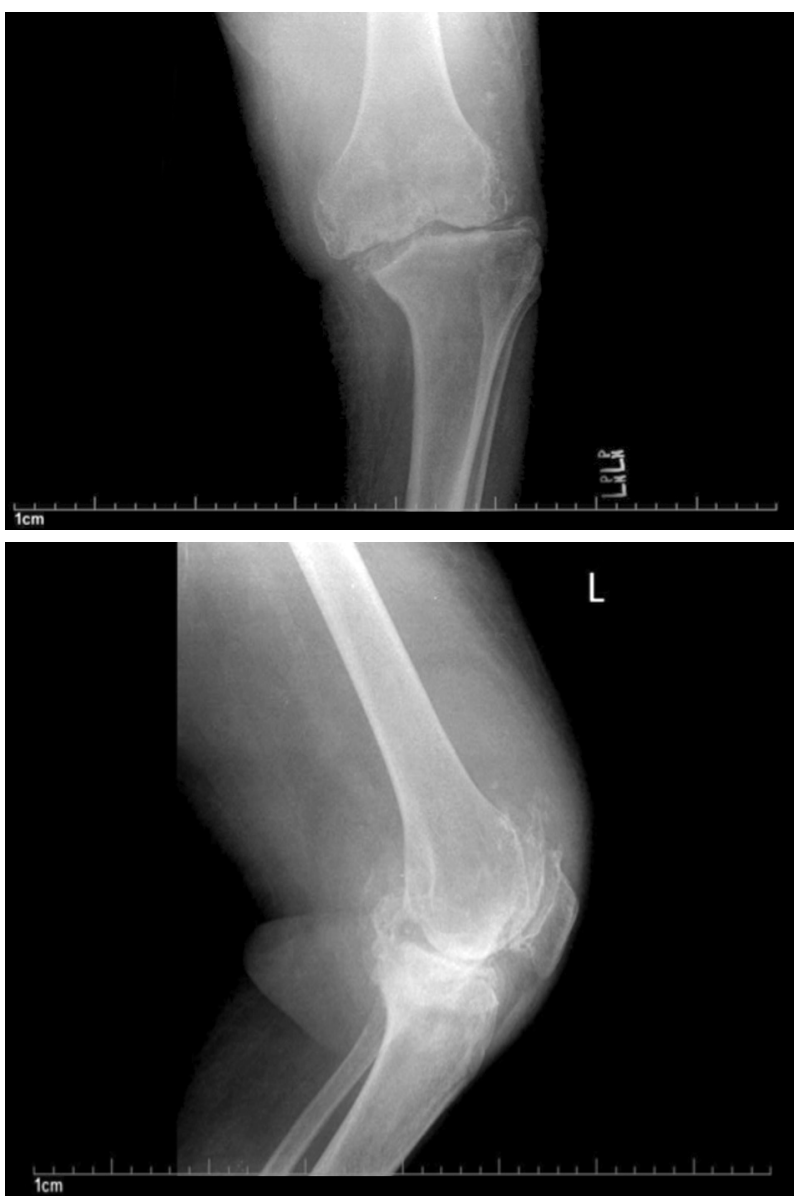

Figure 2. Anteroposterior and lateral X-ray of the left knee showing synovial osteochondromatosis, a large joint effusion and associated arthritic changes with erosions, subchondral cyst formation, heterotopic bone formation, and tibial-femoral subluxation. 


\section{DISCUSSION}

Synovial osteochondromatosis is an uncommon benign condition of unknown etiology, which is characterized by synovial membrane metaplasia, hyperplasia, and hyaline or myxoid change. Loose bodies develop as a result of the proliferation and fragmentation of the synovial lining of the joint, bursa or tendon sheath. These loose bodies get nourished by synovial fluid, and may continue to grow as large as $2-3 \mathrm{~cm}$. Occasionally, they reattach to the synovium and develop a blood supply which allows enchondral bone formation. ${ }^{1-4}$ Sometimes, osteoclastic activity results in spontaneous regression.

The disease is classified into three phases based on the presence or absence of intrasynovial disease. In phase one, only intrasynovial disease is present. In phase two, both intrasynovial nodules and loose bodies are present, and in phase three, loose bodies are present with no active intrasynovial disease. ${ }^{5}$

Primary or idiopathic form may occur in an otherwise normal joint, whereas secondary SOC may occur due to trauma or degenerative diseases. Moreover, it may occur in the setting of preexistent osteoarthritis, rheumatoid arthritis, osteonecrosis, osteochondritis dissecans, neuropathic osteoarthropathy, tuberculosis, or osteochondral fractures. The condition typically presents in young to middle-aged adults. Males are affected twice more frequently than females. ${ }^{6,7}$

Synovial osteochondromatosis is generally a monoarticular condition. The lesions arising from the articular surface typically affect the knee joint followed by the elbow and the hip. ${ }^{8}$ The lesions arising from tendon sheaths most commonly affect the feet and hands. SOC was reported at many unusual locations such as the temporomandibular joint, acromioclavicular joint, ankle joint, wrist joint, spinal facet joints, biceps tendon sheath, and extra-articular locations.

Synovial osteochondromatosis can lead to chronic, progressive pain and swelling in the affected joint as well as a limitation of the range of motion, and often locking. History, physical examination and radiographic data can aid in the diagnosis. The presence of multiple intra-articular loose bodies on plain radiographs should raise suspicion of primary synovial chondromatosis. Furthermore, pressure erosions and cyst formation can be seen in the adjacent bone. ${ }^{9}$ Computed tomography is useful for the detection of the ossified and non-ossified masses, and can show the intra-articular location of the loose bodies. Computed tomography can also be used in cases with equivocal radiographic findings. Additionally, magnetic resonance imaging demonstrates any increased signal on $\mathrm{T}_{2}$-weighted images. ${ }^{10}$

Treatment can involve the surgical removal of the affected synovium and the loose bodies. This condition can likely recur secondary to incomplete removal of the affected synovium. ${ }^{11}$ It has a significant malignant potential to transform into chondrosarcoma (relative risk: $5 \%$ ). ${ }^{12}$

To the best of our knowledge, the bilateral SOC of the knee in a female patient is rare, and this encouraged us to report this case. Secondary synovial chondromatosis should be included in the differential diagnosis of mono-oligoarticular synovitis. Plain radiographs may be normal in the early stages; however, imaging may reveal intra-articular calcification, which are suggestive of loose bodies, as the disease progresses. Chronic knee pain is often attributed to osteoarthritis, thus underlying SOC may be omitted. We conclude that this condition requires further attention due to its association with significant morbidity and risk of malignant transformation to chondrosarcoma.

\section{Declaration of conflicting interests}

The authors declared no conflicts of interest with respect to the authorship and/or publication of this article.

\section{Funding}

The authors received no financial support for the research and/or authorship of this article.

\section{REFERENCES}

1. Milgram JW. Synovial osteochondromatosis: a histopathological study of thirty cases. J Bone Joint Surg [Am] 1977;59:792-801.

2. Sweet DE, Madwell JE. Tumors and tumor-like conditions in or about jonts. In: Resnick D, editor. Diagnosis of bone and joint disorders W.B. Saunders Company 1981. p. 2713-8. 
3. Szepesi J. Synovial chondromatosis of the metacarpophalangeal joint. Acta Orthop Scand 1975;46:926-30.

4. McLennan MK, Ginzberg B, Rubenstein J. Residents' corner. Answer to case of the month \#17. Synovial osteochondromatosis. Can Assoc Radiol J 1993;44:60-2.

5. Madewell JE, Moser RP Jr, Sweet DE. Soft-tissue and joint tumors (benign and malignant). In: Taveras JM, Ferrucci JT, editors. Radiology: diagnosis-imagingintervention. Vol 5. Chapter 102. Philadelphia: JB Lippincott Co, 1988. p. 9-10.

6. Llauger J, Palmer J, Rosón N, Bagué S, Camins A, Cremades R. Nonseptic monoarthritis: imaging features with clinical and histopathologic correlation. Radiographics 2000;20:S263-78.

7. Boles CA, Ward WG Sr. Loose fragments and other debris: miscellaneous synovial and marrow disorders.
Magn Reson Imaging Clin N Am 2000;8:371-90.

8. Yu GV, Zema RL, Johnson RW. Synovial osteochondromatosis. A case report and review of the literature. J Am Podiatr Med Assoc 2002;92:247-54.

9. Annunziata CC, Christoforetti II. Synovial Chondromatosis. EMedicine Website http://emedicine. medscape.com/article/1254671-overview Updated Nov 02, 2009. [Assessed: Nov 28, 2010].

10. Rasheed S, Peh W CG, Chin TW. CME Article. Clinics in Diagnostic Imaging (122). Singapore Med J 2008;49:430-3.

11. Shearer H, Stern P, Brubacher A, Pringle T. A case report of bilateral synovial chondromatosis of the ankle. Chiropr Osteopat 2007;15:18.

12. Davis RI, Hamilton A, Biggart JD. Primary synovial chondromatosis: a clinicopathologic review and assessment of malignant potential. Hum Pathol 1998;29:683-8. 